\title{
Synthesis and Characterization of Chitosan-Acrylic Acid Based Hydrogels and Investigation the Properties of Bilayered Design With Incorporated Alginate Beads
}

\section{Tamara Erceg ( $\nabla$ tamara.erceg@uns.ac.rs )}

University of Novi Sad: Univerzitet u Novom Sadu https://orcid.org/0000-0002-9765-8882

Gaja Brakus

High school Jovan Jovanović Zmaj

\section{Alena Stupar}

University of Novi Sad: Univerzitet u Novom Sadu

Miroslav Cvetinov

University of Novi Sad: Univerzitet u Novom Sadu

Miroslav Hadnađev

University of Novi Sad: Univerzitet u Novom Sadu

Ivan Ristić

University of Novi Sad: Univerzitet u Novom Sadu

\section{Research Article}

Keywords: Chitosan hydrogels, free-radical polymerization, alginate beads, bilayer design, rheological properties

Posted Date: January 12th, 2022

DOI: https://doi.org/10.21203/rs.3.rs-1222045/v1

License: (c) (i) This work is licensed under a Creative Commons Attribution 4.0 International License. Read Full License 


\title{
Synthesis and characterization of chitosan-acrylic acid based hydrogels and investigation the properties of bilayered design with incorporated alginate beads
}

\author{
Tamara Erceg ${ }^{1 *}$, Gaja Brakus ${ }^{2}$, Alena Stupar ${ }^{3}$, Miroslav Cvetinov ${ }^{4}$, Miroslav Hadnađev ${ }^{3}$, Ivan \\ Ristic $^{1}$ \\ ${ }^{1}$ University of Novi Sad, Faculty of Technology Novi Sad, 21000 Novi Sad, Serbia, \\ ${ }^{2}$ High school Jovan Jovanović Zmaj, 21000 Novi Sad, Serbia \\ ${ }^{3}$ University of Novi Sad Institute of Food Technology in Novi Sad, 21000 Novi Sad \\ ${ }^{4}$ University of Novi Sad, Academy of Arts, 21000 Novi Sad \\ Corresponding author: Tamara Erceg, e-mail: tamara.erceg@uns.ac.rs
}

\begin{abstract}
The paper presents the synthesis of hydrogels via free-radical polymerization, based on Chitosan (CS) grafted with Acrylic acid (AA), using a two-step procedure. Free-radical polymerization has given strong hydrogels with compact structure, dominant elastic behavior and long linear viscoelastic region. The results of rheological studies have shown that obtained hydrogels have significantly improved mechanical properties in comparison to chitosan hydrogels obtained by other sustainable methods. A step forward in the investigation of the potential application of chitosan hydrogels in wound dressing systems has been made by preparation of the bilayer design by embedding a layer of active compound-loaded alginate beads into the contact surface between two conjoined units of CS/AA hydrogels. Wild garlic (Allium ursinum L.) dried extract was used as an active compound because of its antimicrobial activity and green properties. This system has
\end{abstract}


demonstrated $\mathrm{pH}$-dependent release of extract and higher shear elastic modulus values than ordinary disc gels. A conducted study has given preliminary results for the possible application of bilayer chitosan - based hydrogels in wound dressing systems and represents the first step towards extrapolating the proposed design across other application fields.

Keywords: Chitosan hydrogels, free-radical polymerization, alginate beads, bilayer design, rheological properties.

\section{Introduction}

Hydrogels are three-dimensional polymer networks that absorb water due to their hydrophilic nature but do not dissolve in it, due to the existence of cross-links between the polymer chains $[1,2]$. The main property of hydrogels is swelling - the ability to absorb the water and increase their volume [3]. Hydrogel swelling behavior depends on polymer chemical structure (the type and amount of hydrophilic groups), polymer-water interaction, crosslinking density, hydrogel porosity, and environmental conditions [4,5]. The presence of hydrophilic groups in hydrogel structure such as hydroxyl (-OH), amide (-CONH-R, $\left.-\mathrm{CONH}_{2}\right)$, and ionizing groups such as amine $\left(-\mathrm{NH}_{2}\right)$ and carboxylic $(-\mathrm{COOH})$ enable the swelling of hydrogel. The ability of hydrogels to respond to changes in $\mathrm{pH}$ and ionic strength in the surrounding medium by changing their absorption properties and volume is based on the ionization of present functional groups [5]. Due to their specific, tailored-made properties such as absorption, the possibility to respond to external stimuli, flexibility in a swollen state similar to natural tissue, hydrogels have received significant attention in the last decades. Hydrogels can be prepared from polymers of different origins, according to which they are divided into natural and synthetic ones [6]. A large amount of nondegradable wastes which comes from synthetic polymers followed by releasing of toxic products and drastic reduction of fossil fuels resources impose ecological and economical requirements for 
using biodegradable materials with improved properties based on renewable resources, such as biopolymers. In addition to water absorption ability, hydrogels are expected to meet other criteria, such as biocompatibility, biodegradability, and non-toxicity [6]. Furthermore, depending on the field of application, other specific properties such as antimicrobial activity could be advantageous in biomedical applications such as wound dressings [7]. Hence, this environmentally pressured reassessment of values has inspired a recent transition to biopolymers in hydrogel preparation. Chitosan is one of the most commonly used natural polymers for hydrogel preparation, obtained by partial deacetylation of chitin in an alkaline medium. Chitin is a natural polysaccharide and following cellulose, the most abundant polymer [6]. Due to its excellent biocompatibility and antimicrobial properties, chitosan-based hydrogels are being thoroughly considered for biomedical applications. They are especially promising in the field of wound dressing systems, because, in addition to the listed properties, chitosan accelerates wound healing by stimulating immune response [8], promoting the wound contraction [6] having the hemostatic and anticoagulant properties [6,9]. Permanent (chemically cross-linked) chitosan hydrogels can be obtained using different cross-linkers able to react with chitosan groups such as glutaraldehyde $[10,11]$ genipin [12] ethylene glycol di-glycidyl ether (EGDE) [13]. Additionally, a cross-linking reaction can be carried out after grafting of the chitosan. Therefore, according to the functional groups introduced in the chitosan backbone by grafting, different types of cross-linkers can be employed in hydrogel synthesis $[14,15]$. However, hydrogels obtained in this way (via a one-step reaction process between functional groups) have poor mechanical properties which limit their application as hemostatic gauzes, while the non-specific response to $\mathrm{pH}$ limits their application as drug delivery systems. Chitosan gels can also be obtained by a photo-crosslinking which is performed under the UV light in the presence of a chemical photoinitiator [7]. Hydrogels obtained in this way have a 
stronger structure, but lower flexibility [7]. Ionizing radiation is a powerful tool for obtaining chemically crosslinked hydrogels for biomedical applications enabling simultaneous sterilization [16]. This method does not require the addition of crosslinking agent; the final hydrogel contains only chitosan and possesses good mechanical properties [7]. However, this process requires expensive equipment and installations. Accordingly, an ideal wound dressing should possess specific properties of chitosan hydrogel, enabling gaseous exchange, maintaining wound moisture, and removing the excess of exudates. It is also very important that the hydrogels can be fabricated from available material, using economical and simple procedures [6]. Numerous authors have proposed grafting of chitosan by polyacrylic acid by the mechanism of free-radical polymerization which implies the production of macro-radicals in the reaction of chitosan and initiator radicals, which initiate the vinyl monomer to polymerize [17-19]. Guided by these principles, hydrogels based on chitosan grafted by acrylic acid have been synthesized in this research using a simple and economical two-step method; the first step has resulted in grafted chitosan with incorporated double bonds, able to form a strong hydrogel in the second step via free-radical polymerization, in the presence of the crosslinking agent. Chitosan is a cationic polymer due to its amino groups. However, these groups are employed in the grafting process as well as the carboxylic groups of acrylic acid, resulting in a hydrogel that is not $\mathrm{pH}$ sensitive. This shortcoming has thus far hindered the development of chitosan-based drug delivery systems and limited the use of chitosan-based dressings for chronic wound clinical treatment, despite the commercial success of their counterparts designed for acute wounds. Therefore, the goal is to obtain a completely biocompatible, chitosan-based hydrogel system under mild reaction conditions, using a green path, which shows the $\mathrm{pH}$-dependent delivery of the active compound. The aim of this work is a contribution to solving this issue, by introducing a novel sustainable drug delivery system, 
consisting of a CS/AA hydrogel shell and entrapped drug-loaded alginate beads. Sodium alginate is a pH-sensitive anionic polysaccharide. Carboxylic groups are in the anionic form above the $\mathrm{pKa}$ values of alginate constitutive units - guluronic $\left(\mathrm{pK}_{\mathrm{a}} 3.38\right)$ and mannuronic acid $\left(\mathrm{pK}_{\mathrm{a}} 3.65\right)$ leading to the expansion of alginate-based network and water uptake. Under this value, the carboxylic groups are not ionized, and in such form do not contribute to swelling [20, 21]. The design is termed bilayer because it is prepared by embedding a layer of active compound-loaded beads into the contact surface between two conjoined units of CS/AA hydrogels. The unique architecture of the proposed delivery platform allows for exploiting all the proven virtues of chitosan wound dressing systems, enabling $\mathrm{pH}$-dependent drug release from the alginate beads within which the active compound is contained. Releasing profile of bilayer sample was investigated using the wild garlic (dried extract incorporated in alginate beads as colored, bio-based, water-soluble substance, with proved antimicrobial effect, obtained from widely available weed plant using a green extraction process. This selection of compounds and methods of preparation have put the whole process in an ecological framework, guided by the principles of green chemistry and exploitation of low-cost raw materials for the preparation of valuable products. According to our best knowledge, swelling kinetics of chitosan-graft-acrylic acid-based hydrogels obtained in this way is not reported in the available literature, as well as a deeper consideration of their rheological properties; therefore this paper gives established parameters of swelling kinetics - determined diffusion type, swelling kinetics order of hydrogels based on chitosan grafted by acrylic acid obtained via free-radical polymerization and thoroughly studied rheological properties. Also, bilayer-designed chitosan hydrogel prepared in this way and aimed in this purpose has not been described in the available literature. 


\section{Experimental section}

\subsection{Materials}

Chitosan (CS, $\mathrm{M}_{\mathrm{w}}=100,000-300,000 \mathrm{~g} / \mathrm{mol}$, degree of deacetylation $\geq 75 \%$ ), Acrylic acid (AA, p.a.) and Glacial acetic (p.a.) acid were supplied from Acros Organic (New Jersey, USA). N,N'methylenebisacrylamide (MBAM) was purchased from Sigma-Aldrich (St. Louis, MO USA), while potassium persulfate (PPS) was delivered from Centrohem (Stara Pazova, Serbia). Distilled water with added glacial acetic acid was used for chitosan dissolution and a medium for the polymerization reaction. The swelling behavior of obtained hydrogels was investigated in citric ( $\mathrm{pH} 3$ ) and phosphate ( $\mathrm{pH}$ 7.4) buffer solution (Alfapanon, Bački Petrovac, Serbia). Wild garlic extract in powder state prepared according to the procedure described in Section 2.4. [22]. Antibacterial activity of extract water solution was investigated according to the procedure described in Section 2.5.[22].

\subsection{Preparation of Chitosan/Acrylic acid hydrogels}

For the preparation of CS/AA hydrogels, chitosan (in the amount of $4.5 \% \mathrm{w} / \mathrm{w}$ ) was added to the solution of acetic acid in distilled water $(\mathrm{pH} 4.5)$ at about $75^{\circ} \mathrm{C}$. After the complete dissolution of chitosan, acrylic acid was added in a certain amount (Table 1). After 60 min of simultaneous homogenization and amidation/esterification, cross-linker MBAM and initiator PPS completely dissolved in distilled water ( $1 \mathrm{wt} \%$ aqueous solution) was added to the solution of CS grafted with AA. Crosslinking reaction was completed for $40 \mathrm{~min}$. Obtained hydrogels were purified by distilled water (gels were been rinsed until the water was not completely clear) in order to remove unreacted acrylic acid, cross-linking agent, and chitosan. In order to investigate the influence of cross-linker amount on the properties of obtained hydrogels, one series with the same CS/AA ratio 
was synthesized by varying the cross-linker amount (1, 2, and $3 \mathrm{wt} \%$ per AA weight). Obtained hydrogels were dried in a vacuum at $50^{\circ} \mathrm{C}$ until constant weight.

Table 1. The initial amount of components for the synthesis of CS/AA hydrogels.

\begin{tabular}{|c|c|c|c|c|c|}
\hline $\begin{array}{l}\text { Sample } \\
\text { name }\end{array}$ & Compounds & CS & $\mathbf{A A}$ & $\begin{array}{c}\text { MBAM (\% per } \\
\text { AA weight) }\end{array}$ & $\begin{array}{l}\text { PPS \% } \\
\text { (per AA } \\
\text { weight) }\end{array}$ \\
\hline $15 / 85,2 \%^{a}$ & \multirow{5}{*}{$\begin{array}{c}\text { Initial } \\
\text { weight ratio }\end{array}$} & 15 & 85 & 2 & \multirow{5}{*}{2.5} \\
\hline $20 / 80,1 \%^{\mathrm{b}}$ & & \multirow{3}{*}{20} & \multirow{3}{*}{80} & 1 & \\
\hline $20 / 80,2 \%^{c}$ & & & & 2 & \\
\hline $20 / 80,3 \%^{d}$ & & & & 3 & \\
\hline $25 / 75,2 \%^{\mathrm{e}}$ & & 25 & 75 & 2 & \\
\hline
\end{tabular}

a $15 / 85,2 \%$ - sample based on $15 \mathrm{wt} \%$ of Chitosan, $85 \mathrm{wt} \%$ of Acrylic acid and $2 \mathrm{wt} \%$ of MBAM per weight of Acrylic acid

b 20/80, 1\% - sample based on 20 wt $\%$ of Chitosan, 80 wt $\%$ of Acrylic acid and $1 \mathrm{wt} \%$ of MBAM per weight of Acrylic acid c 20/80, 2\% - sample based on 20 wt $\%$ of Chitosan, 80 wt $\%$ of Acrylic acid and 2 wt $\%$ of MBAM per weight of Acrylic acid d 20/80, 3\% - sample based on 20 wt $\%$ of Chitosan, 80 wt $\%$ of Acrylic acid and $3 \mathrm{wt} \%$ of MBAM per weight of Acrylic acid e 25/75, 2\% - sample based on $25 \mathrm{wt} \%$ of Chitosan, $75 \mathrm{wt} \%$ of Acrylic acid and $2 \mathrm{wt} \%$ of MBAM per weight of Acrylic acid

\subsection{Preparation of calcium alginate beads}

Sodium alginate was dissolved in distilled water at about $70{ }^{\circ} \mathrm{C}(1.5 \% \mathrm{w} / \mathrm{w})$. Calcium alginate beads were formed using an automatic pipette to drip $25 \mu \mathrm{l}$ of alginate solution in calcium-chloride $\left(\mathrm{CaCl}_{2}\right)$ water solution $(3 \% \mathrm{w} / \mathrm{w})$. The beads were formed via the complexation of alginate by $\mathrm{Ca}^{2+}$ ions. After stirring for $1 \mathrm{~h}$ at room temperature, formed beads were kept overnight in calciumchloride gelling solution in order to ensure the optimal level of crosslinking, i.e. strongly gelled alginate beads. Formed beads were separated from $\mathrm{CaCl}_{2}$ solution by filtration method, rinsed with distilled water two times in order to remove $\mathrm{Ca}^{2+}$ and $\mathrm{Cl}^{-}$ions from the surface of beads, and dried at about $45^{\circ} \mathrm{C}$ until constant weight. 


\subsection{Preparation of wild garlic dry extract}

Dried and chopped leaf wild garlic was subjected to extraction by subcritical water at $160{ }^{\circ} \mathrm{C}$ for 20 min (extractor Parr Instrument Company, SAD). All extractions were performed under isobaric conditions at 36 bar. The drug-solvent ratio was remained constant in all experiments at 1:10 (m/v). After extraction, the extractor was cooled in an ice bath to room temperature. After cooling, the extracts were immediately filtered through filter paper. The obtained liquid extract was dried by spray drying technique on a semi-industrial device Anhydro spray dryer (APV Anhydro AS, Denmark). Maltodextrin (DE 19.7) was used as a drying agent and carrier in the drying process in a concentration of $40 \%$ relative to the dry residue of the liquid extract. Feed mixture was prepared by homogenization of maltodextrin solution in water and liquid extract of wild garlic [22].

\subsection{Antimicrobial activity of wild garlic extract}

For investigation of antibacterial activity of the aqueous extract of wild garlic - Allium ursinum L. powder the following bacterial species were used: Salmonella Typhimurium, Salmonella Enteritidis, Escherichia coli, Proteus hauseri. Commercial species purchased in the lyophilized state were stored in the refrigerator until the moment of activation. Once a week, the cultures were refreshed by inoculation of nutrient agar (Himedia, India) and safely removed after one month. Working cultures are prepared from the corresponding subcultures by inoculation on nutrient agar and incubation at $37{ }^{\circ} \mathrm{C}$ for $18-24 \mathrm{~h}$. Samples with extract solution were contaminated by test microorganisms, incubated $24 \mathrm{~h}$ at $37{ }^{\circ} \mathrm{C}$ in nutrient broth under aerobic conditions. After incubation, test number of microorganisms in the tested samples were determined using the drop plate method $[22,23]$. The results of the antibacterial test of the examined supercritical extract have shown an inhibitory effect on all species of tested bacteria. After 24 hours, bacterial colonies were not detected in the test sample. 


\subsection{Preparation of filled alginate beads}

Wild garlic extract was dissolved in alginate solution in a predicted amount. After homogenization and cooling, calcium alginate beads filled with extract were formed in the same way as it is explained in Section 2.3.

\subsection{Preparation of bilayer hydrogel embedded with alginate beads}

Bilayer hydrogels were prepared by forming a top layer on the surface of a previously formed bottom layer in the swollen state with alginate beads on the contact surface of the layers (Fig. 1). The reaction mixture just before reaching the gel point was poured over the bottom layer with alginate beads on the contact surface. The bottom layer was prepared according to the previously described procedure in Section 2.2., using the CS/AA in initial ratio 20/80, with $2 \mathrm{wt} \%$ of crosslinking agent, as hydrogel with optimized properties. Bilayer samples were prepared with and without extract in alginate beads in order to investigate the delivery of extract at two different $\mathrm{pH}$ values using two kinds of biopolymer hydrogels with different geometry united in the new design.

Figure 1. Preparation of bilayer hydrogel.

\subsection{Fourier Transform Infrared (FTIR) spectroscopy}

The chemical structure of prepared hydrogels was analyzed using the IRAffinity-1S Fourier Transform Infrared (FTIR) spectrophotometer (Shimadzu) by ATR technique in transmission mode. The spectra were recorded in the infrared region $4000-400 \mathrm{~cm}^{-1}$.

\subsection{Scanning electron microscopy}

The microstructures of hydrogels were analyzed using a scanning electron microscope (JEOL JSM-6460, Japan) with an accelerating voltage of $20 \mathrm{kV}$. Xerogel samples were immersed in liquid nitrogen, cut, gold-sputter coated, and examined at different magnifications. 


\subsection{Swelling analysis}

\subsubsection{Swelling ratio}

The swelling behavior of synthesized disc hydrogels was investigated at two pH values ( 3 and 7.4), at room temperature $\left(25^{\circ} \mathrm{C}\right)$, and at physiological temperature $\left(37^{\circ} \mathrm{C}\right)$. Preweighed xerogels (completely dried hydrogels) were immersed in buffer solution and in certain time intervals (15, $30,60,120,180,240,300 \mathrm{~min})$ the swollen hydrogel discs were pulled out, wiped superficially, and weighed. Swelling ratio $(\mathrm{S})$ at different time intervals was determined using the following Equation 1:

$S=\frac{W_{t}-W_{o}}{W_{0}} \cdot 100 \%$

where $\mathrm{W}_{\mathrm{t}}$ is the weight of swollen hydrogel in a certain time, and $\mathrm{W}_{0}$ is the initial weight of xerogel. All tests were carried out in triplicate and average values were considered.

\subsubsection{Diffusion of water}

A type of solvent diffusion was studied using the following empirical model (Equation 2) [24]:

$F=\frac{s}{s_{e}}=k \cdot t^{n}$

Where $F$ is a swelling fraction, $S$ is swelling ratio in time $\mathrm{t}$ and Se is equilibrium swelling ratio; $k$ is a constant dependent on polymer network structure and $n$ is a diffusional exponent which provides information about solvent sorption, i.e. diffusion type. The value of $n$ is determined from the slope of natural logarithm transformed Equation 2 which gives precise analysis for the fractional values up to 0.6 . If $n$ has a value between 0 and 0.5 , sorption is diffusion-controlled, or Fickian, which means that solvent diffusion into hydrogel matrix is slower than the relaxation of 
polymer chains. If $n$ has a value above 0.5 , diffusion is non-Fickian, or relaxation controlled, which means that diffusion of solvent is faster than the relaxation of polymer chains of hydrogel [25].

\subsubsection{Swelling kinetics}

Based on the behavior of samples during the manipulation within swelling ratio measurements and obtained results, swelling kinetics is analyzed with the assumption that the swelling follows second order kinetics described by the following Equation 3 [26]:

$$
\frac{d S}{d t}=K_{2}\left(S_{e}-S\right)^{2}
$$

where $S$ is swelling ratio at time t, $S_{e}$ is equilibrium swelling ratio and $K_{2}\left(\mathrm{~min}^{-1}\right)$ is constant of second-order kinetics. A constant decreases with decreasing in swelling rate. After integrating the Equation 3 for the initial conditions ( $t$ from 0 to $t$ and $S$ from 0 to $S$ ) the following Equation 4 is obtained:

$\frac{t}{S}=\frac{1}{K_{2} S_{e}^{2}}+\frac{1}{S_{e}} t$

\subsection{Determination of gel fraction}

At the end of the swelling experiments, hydrogel discs were dried in a vacuum dryer until constant weight and reweighed. The gel fraction was determined using the following Equation 5:

$$
\text { Gel Fraction }=\frac{W^{\prime}}{W_{0}} \cdot 100 \%
$$

where $\mathrm{W}^{\prime}$ is the weight of dried hydrogels and $W_{0}$ is the initial weight of xerogel. All tests were carried out in triplicate and average values were considered. 


\subsection{Rheology}

Rheological characterization of hydrogels was performed using a Haake Mars rheometer (Thermo Scientific, Karlsruhe, Germany), with PP35 Ti plate-plate geometry with 35 diameter at $25 \pm 0.1$ ${ }^{\circ} \mathrm{C}$. The gap between plates was kept at $25 \mathrm{~mm}$. After the samples stopped being adherent, hydrogels were subjected to the first series of dynamic-mechanical measurements. Before the second series of measurements was carried out, disc-shaped hydrogels (after drying and syneresis) were equilibrated in acidic buffer at room temperature. In order to determine shear elastic (G') and viscous $\left(G^{\prime \prime}\right)$ moduli of hydrogels in the linear viscoelastic regime, oscillatory frequency sweep tests were performed in the frequency range from 0.1 to $10 \mathrm{~Hz}$, at constant stress of 10.00 . Oscillatory stress tests were carried out in the stress range from 1 to $10,000 \mathrm{~Pa}$, at a constant frequency of $1 \mathrm{~Hz}$ in order to determine the hydrogel strength in a swollen state. Measurements were carried out in triplicate and average values were graphically presented. The loss tangent $(\tan \delta)$, which indicates the relative degree of energy dissipation of hydrogels and bilayered system, represents the ratio between shear viscous and elastic modus is calculated using Equation 6:

$\tan \delta=\frac{G^{\prime \prime}}{G^{\prime}}$

Viscoelastic behavior of hydrogels can be also described by complex shear viscosity ( using the following Equation 7, where f represents linear frequency expressed in $\mathrm{Hz}$.

$\eta^{*}=\sqrt{\left(\frac{G^{\prime}}{f}\right)^{2}+\left(\frac{G^{\prime \prime}}{f}\right)^{2}}$

The complex viscosity - linear frequency dependence is described using the regression analysis, assuming the equation for a giving empirical dependence. The parameter of function which describe the variation of complex shear viscosity in function of time are calculated using the Equation 8 and 9: 


$$
\begin{aligned}
b_{1} & =\frac{n \cdot \sum_{i}^{n} x_{i} \times y_{i}-\left(\sum_{i}^{n} x_{i}\right)\left(\sum_{i}^{n} y_{i}\right)}{n \cdot \sum_{i}^{n} x_{i}^{2}-\left(\sum_{i}^{n} x_{i}\right)^{2}} \\
b_{0} & =\frac{1}{n}\left(\sum_{i}^{n} y_{i}-b_{1} \cdot \sum_{i}^{n} x_{i}\right)
\end{aligned}
$$

where $\mathrm{x}$ and $\mathrm{y}$ are variables in a regression analysis, $b_{1}$ is $a$ and $\ln b_{0}$ is $b$.

Results of frequency sweep test enable determination of mesh size ( $\xi$ ) using the Equation 10 [27]:

$\xi=\left(\frac{k_{b} \cdot T}{G_{e}}\right)^{\frac{1}{3}}$

Where $k_{b}$ is the Boltzmann constant and $T$ is an absolute temperature and $G_{e}$ is plateau value of shear elastic modulus.

\subsection{Delivery studies}

The ability of bilayer hydrogels to deliver extract incorporated in alginate beads was investigated at two $\mathrm{pH}$ values $\left(3\right.$ and 7.4 ) at $37^{\circ} \mathrm{C}$, considering different swelling properties of alginate beads at different $\mathrm{pH}$ values. Bilayered xerogels were immersed in buffer solutions ( $\mathrm{pH} 3$ and $\mathrm{pH} 7.4$ ) and in certain time intervals $(30,60,90,120,150,180 \mathrm{~min})$, hydrogels were removed from the buffer and the color of the buffer solution was determined using a Konica Minolta Chromameter. The parameters $L^{*}$ (lightness), a* (red-green), and $b^{*}$ (yellow-blue) were firstly read for the blank tan solutions using a D65 light source and the white calibration plate. Blank tans were obtained by immersing the bilayer hydrogels without extract in buffer solutions ( $\mathrm{pH} 3$ and $\mathrm{pH} 7.4)$ and removing them after $180 \mathrm{~min}$. Every $30 \mathrm{~min}$, after bilayer hydrogel was taken out, the values of parameter $L^{*}, a^{*}, b^{*}$ were read. The color difference between buffer solution in a certain time interval and blank tan $\left(\Delta \mathrm{E}^{*} \mathrm{ab}\right)$ was calculated by the following Equation 11:

$$
\Delta \mathrm{E}_{\mathrm{ab}}^{*}=\sqrt{\left(\Delta L^{*}\right)^{2}+\left(\Delta a^{*}\right)^{2}+\left(\Delta b^{*}\right)^{2}}
$$


where $\Delta \mathrm{L}^{*}$ is the difference in lightness between buffer solution in certain time interval and blank tan buffer solution, $\Delta a^{*}$ and $\Delta b^{*}$ the difference in coordinates green/red and blue/yellow [28]. For each sample (buffer in certain time interval) three values are noted and the average value was taken into consideration. All tests were carried out in triplicate and average values were considered. This method was implemented for the investigation of bilayer delivery properties as a fast, simple and relevant procedure to confirm its main ability $-\mathrm{pH}$ sensitive releasing of used extract.

\subsection{Differential scanning calorimetry}

The phase transitions of xerogel samples were determined using the Q20, TA Instruments differential scanning calorimeter. The measurements were performed in the atmosphere of nitrogen at a flow rate of $50 \mathrm{ml} / \mathrm{min}$ in the temperature range from 25 to $250{ }^{\circ} \mathrm{C}$; the heating rate was $10^{\circ} \mathrm{C} / \mathrm{min}$.

\subsection{Thermal gravimetric analysis (TGA)}

The thermal stability of xerogel samples was analyzed using the LECO 701 Thermogravimetric Analyzer. The samples were heated in the air atmosphere, from 25 to $800{ }^{\circ} \mathrm{C}$ at a heating rate of $10{ }^{\circ} \mathrm{C} / \mathrm{min}$.

\subsection{6. $X$-ray diffraction analysis $(X R D)$}

The microstructure of xerogel samples was investigated by Philips PW1820 X-ray Diffractometer, which operates at a voltage of $30 \mathrm{kV}$ and a current of $30 \mathrm{~mA}$ using $\mathrm{CuK} \alpha$ radiation. Data were obtained in the $2 \theta$ range of $5-40^{\circ}$. Peak position calibration and determination of instrumental peak broadening were performed using a $\mathrm{LaB}_{6}$ as an external standard. The average interchain spacing $(<R>)$ for xerogel samples was calculated using Equation 12 in order to investigate the influence of the initial ratio of components on the chain arrangement in the amorphous phase [29]. 
$<R>=\frac{5}{8}\left(\frac{\lambda}{\sin \theta}\right)$

\subsection{Statistical analysis}

The statistical analysis of experimental data was carried out using Microsoft Excel 2010 and OriginPro 8. Average values, standard deviation, and range of the obtained swelling ratio, gel fraction, color parameter and plateau elastic modulus values are calculated in Excel, while Standard Error - values for intercept and slope of linear fitted curves were determined in Origin.

\section{Results and discussion}

\subsection{Preparation of hydrogels}

Fig. 2 ilustrates the proposed reaction mechanism of CS-graft-AA hydrogels synthesis, according to conducted FTIR and swelling studies. The reaction of grafting is carried out via the formation of the ester and amide bonds between hydroxyl or amino groups of CS and carboxylic groups of AA in an acidic medium. Grafting reaction enables obtaining of modified CS with double bond able to form polymer network via free-radical polymerization in the presence of MBAM as a crosslinking agent.

Figure 2. Proposed reaction mechanism of CS-graft-AA hydrogels synthesis.

\subsection{FTIR analysis}

Two peaks at approximately 3360 and $3230 \mathrm{~cm}^{-1}$ noticed in the FTIR spectrum of the graft copolymer (Fig. 3I) and hydrogels spectra (Fig. 3II and III) correspond to the asymmetrical and symmetrical stretching vibration of $-\mathrm{NH}_{2}$ group. By comparison of the transmittance values of these peaks for hydrogels synthesized using the different amounts of crosslinking agent MBAM (Fig. 3III) it can be observed that it decreases with increasing in MBAM amount in hydrogel 
composition. The lower transmittance value is the result of a higher network density, i.e. higher population of chemical bonds whose vibrational frequencies match the frequencies of incoming light [30]. The broad peak in the range $3600-3000 \mathrm{~cm}^{-1}$ corresponds to $-\mathrm{OH}$ stretching. The absorption peaks at around 2920 and $2890 \mathrm{~cm}^{-1}$ are attributed to $-\mathrm{C}-\mathrm{H}$ asymmetric and symmetric stretching vibrations. The peak at 1720 is attributed to the $-\mathrm{C}=\mathrm{O}$ group from the ester bond and peak at 1640 corresponds to the $-\mathrm{C}=\mathrm{O}$ group from the amide bond. A small peak at $1630 \mathrm{~cm}^{-1}$ visible in the IR spectrum of copolymer (Fig. 3Ia) is attributed to $-\mathrm{C}=\mathrm{C}$ asymmetric stretching. Band at $1560 \mathrm{~cm}^{-1}$ corresponds to $-\mathrm{N}-\mathrm{H}$ banding vibrations from the amide linkage while band at $1410 \mathrm{~cm}^{-1}$ corresponds to $-\mathrm{C}-\mathrm{O}-\mathrm{H}$ bending. The peak at $1320 \mathrm{~cm}^{-1}$ corresponds to the $-\mathrm{C}-\mathrm{O}-\mathrm{H}$ bending and $\mathrm{CH}_{2}$ twisting. The peak at about $1210 \mathrm{~cm}^{-1}$ is attributed to the $\mathrm{C}-\mathrm{O}$ and $\mathrm{C}-\mathrm{N}$ stretching. Two peaks at 1050 and $1020 \mathrm{~cm}^{-1}$ correspond to -C-C-O stretching and -C-O-H deformation. Bending vibrations of $=\mathrm{C}-\mathrm{H}$ and $=\mathrm{CH}_{2}$ group appear as peaks at 985,885 , and $780 \mathrm{~cm}^{-1}$ in IR spectrum of copolymer; their absence in hydrogel spectra confirms crosslinking via free-radical polymerization. A broad peak at about $710 \mathrm{~cm}^{-1}$ is attributed to $-\mathrm{NH}$ bending (out-of-plane) [31]. There are no differences between FTIR spectra of synthesized hydrogels in terms of present peaks.

Figure 3. FTIR spectra of:

I a) CS/AA copolymer 20/80, b) CS/AA hydrogel 20/80; II CS/AA hydrogels a) $15 / 85,2 \%$, b) $20 / 80,2 \%$, c) $25 / 75,2 \%$

III a) $20 / 90,1 \%$, b)20/80, $2 \%$, c) $20 / 80,3 \%$

\subsection{Scanning electron microscopy studies}

During hydrogels drying, syneresis has been observed. Under the available magnifications, the hydrogel pores could not be detected. Fig. 4 shows the compact inner structure of hydrogels, with 
no differences related to the chemical composition. SEM micrographs of alginate beads at different magnifications (Fig. 5) reveals rough, porous surface with network of fissures and protrusions visible at higher magnifications (Fig. $5 b$ and c).

Figure 4. SEM images of CS/AA hydrogels at magnification 10000: a) hydrogel 15/85, 2\% , b) hydrogel $20 / 80,2 \%$, c) $25 / 75,2 \%$ d) $20 / 80,1 \%$, e) $20 / 80,3 \%$.

Figure 5. SEM images of alginate beads at different magnifications.

Swelling properties were investigated at two $\mathrm{pH}$ values ( 3 and 7.4) and two temperatures (25 and $37{ }^{\circ} \mathrm{C}$ ) in order to determine the influence of chemical composition on the formation and functionalization of the polymer network. Hydrogel with a greater amount of AA $(15 / 85,2 \%)$ has shown the greater swelling capacity at both $\mathrm{pH}$ and temperature values in comparison to hydrogel 20/80 and 25/75 because of a higher concentration of amide groups (Fig. 6a and c and Fig. S1a and c). A similar swelling pattern at different $\mathrm{pH}$ values indicates that protonated amino groups had reacted with the carboxylic groups of AA, which has resulted in amide linkages, because increasing in AA amount in copolymer composition leads to the increase in hydrogel swelling ratio; $\mathrm{pK}_{\mathrm{b}}$ of amide groups is about 14, which means that under this value (at $\mathrm{pH} 3$ and $\mathrm{pH}$ 7.4), amide groups are in ionized form. A greater amount of acrylic acid in hydrogel composition implies an increased concentration of amide groups originates from the reaction of acrylic acid and chitosan amine groups, as well as of the amide groups which originate from crosslinking agent MBAM [32]. Hydrogel 20/80 and 25/75 have very similar swelling behavior at both $\mathrm{pH}$ values. Comparison the swelling ability of hydrogels with the same CS/AA ratio, but different amount of crosslinking agent MBAM, it was revealed that hydrogel with 1wt\% of MBAM has had the 
greatest swelling capacity, which is the consequence of the lowest crosslinking density (Fig. $6 \mathrm{~b}$ and d and Fig. S1b and c). Hydrogel synthesized with 3wt\% of MBAM has shown the lowest swelling capacity, which is the consequence of high crosslinking density. Hydrogels in general have shown a little bit better swelling capacity at physiological pH (Fig. 6b and d, Fig. S1b and d). Hydrogels manifest better swelling capacity at higher, physiological temperature (Fig. S1) which is a consequence of a higher rate of water diffusion and better penetration into the hydrogel matrix. The results of swelling behavior are in accordance with FTIR and SEM studies.

Figure 6. Swelling ratio as a function of time for CS/AA hydrogels at room temperature a) with different amount of grafted $\mathrm{AA}$ at $\mathrm{pH} 3, \mathrm{~b}$ ) with different amount of cross linking agent at $\mathrm{pH} 3$, c) with different amount of grafted $\mathrm{AA}$ at $\mathrm{pH} 7.4$, d) with different amount of crosslinking agent at $\mathrm{pH} 7.4$.

The mechanism of solvent diffusion into the hydrogel matrix was investigated using Equation 2. Natural logarithm values of $F(\operatorname{lnF})$ and $t(\operatorname{lnt})$ were plotted and $n$ values is determined from the slope for both $\mathrm{pH}$ values and room temperature (Fig. S2 and S3, Supporting Information) and presented in Table 2 for both temperatures. Obtained $n$ values are above 0.5 , indicating a nonFickian or relaxation-controlled mechanism of solvent diffusion, which implies that hydrogels swelling has carried out at temperatures which is below the glass transition temperature $\left(\mathrm{T}_{\mathrm{g}}\right)$ of xerogels.

Table 2. The diffusional exponent ( $n$ ) values for CS/AA hydrogel samples ( $\mathrm{pH} 3$ and 7.4, at room temperature and physiological temperature). 


\begin{tabular}{|c|c|c|c|c|}
\hline \multirow{2}{*}{ Sample } & \multicolumn{4}{|c|}{$\boldsymbol{}$} \\
\cline { 2 - 5 } & $\mathrm{pH} \mathrm{3,25}{ }^{\circ} \mathrm{C}$ & $\mathrm{pH} \mathrm{7.4,25}{ }^{\circ} \mathrm{C}$ & $\mathrm{pH} \mathrm{3,37}{ }^{\circ} \mathrm{C}$ & $\mathrm{pH} \mathrm{7.4,37}{ }^{\circ} \mathrm{C}$ \\
\hline $15 / 85,2 \%$ & 0.83 & 0.60 & 0.51 & 0.73 \\
\hline $20 / 80,2 \%$ & 0.52 & 0.53 & 0.54 & 0.53 \\
\hline $25 / 75,2 \%$ & 0.55 & 0.51 & 0.55 & 0.59 \\
\hline $20 / 80,1 \%$ & 0.51 & 0.51 & 0.51 & 0.56 \\
\hline $20 / 80,3 \%$ & 0.52 & 0.53 & 0.51 & 0.56 \\
\hline
\end{tabular}

In order to assess if the swelling of CS/AA hydrogels follows the second-order kinetics, the $\mathrm{t} / \mathrm{S}$ values from Equation 4 were plotted against the time (Fig. S4 and S5, Supporting Information). The $K_{2}$ values were determined from the intercept (Table 3). Swelling data fit a straight line for all samples at both $\mathrm{pH}$ values and temperatures, which supports the claim that swelling of CS/AA hydrogels follows the second-order kinetics.

Table 3. Estimated $K_{2}$ values for the second - order kinetics (Equation 4).

\begin{tabular}{|c|c|c|c|c|}
\hline \multirow{2}{*}{ Sample } & \multicolumn{4}{|c|}{$K_{2}\left(\min ^{-1}\right)$} \\
\hline & $\mathrm{pH} 3,25^{\circ} \mathrm{C}$ & $\mathrm{pH} 7.4,25^{\circ} \mathrm{C}$ & $\mathrm{pH} 3,37^{\circ} \mathrm{C}$ & $\mathrm{pH} 3,37^{\circ} \mathrm{C}$ \\
\hline $15 / 85,2 \%$ & $2.31 \cdot 10^{-4}$ & $1.45 \cdot 10^{-4}$ & $3.36 \cdot 10^{-4}$ & $8.07 \cdot 10^{-5}$ \\
\hline $20 / 80,2 \%$ & $6.30 \cdot 10^{-4}$ & $5.26 \cdot 10^{-4}$ & $4.20 \cdot 10^{-4}$ & $2.16 \cdot 10^{-4}$ \\
\hline $25 / 75,2 \%$ & $4.92 \cdot 10^{-4}$ & $5.34 \cdot 10^{-4}$ & $3.78 \cdot 10^{-4}$ & $6.03 \cdot 10^{-4}$ \\
\hline $20 / 80,1 \%$ & $4.91 \cdot 10^{-4}$ & $5.11 \cdot 10^{-4}$ & $3.74 \cdot 10^{-4}$ & $3.71 \cdot 10^{-4}$ \\
\hline $20 / 80,3 \%$ & $6.30 \cdot 10^{-4}$ & $6.34 \cdot 10^{-4}$ & $4.71 \cdot 10^{-4}$ & $5.06 \cdot 10^{-4}$ \\
\hline
\end{tabular}

Considering the potential application in wound dressing systems, the swelling behavior of bilayered hydrogel was investigated at two $\mathrm{pH}$ values and physiological temperature. Bilayered hydrogel has a greater swelling capacity at $\mathrm{pH} 7.4$ (Fig. 7) due to the presence of alginate beads in its structure which swell above the $\mathrm{pK}_{\mathrm{a}}$ value of the alginic acid constitutive units. The swelling pattern is less regular in comparison to monolayer hydrogel, but values of swelling ratio are greater due to the larger contact surface between hydrogel and buffer solution. 
Figure 7. Swelling ratio as a function of time for bilayered hydrogel at physiological temperature and different $\mathrm{pH}$ values $(\mathrm{pH} 3$ and $\mathrm{pH}$ 7.4).

\subsection{Results of gel fraction study}

Gel fraction of hydrogels is given in Table 9 in section Statistical analysis. High values of gel fraction imply optimal initial composition of hydrogels and high yield of the reaction. Hydrogel 20/80 with $2 \%$ of MBAM has a greater value of gel fraction, which indicates that this sample has adequately optimized composition. Bilayered hydrogel composed of two hydrogels 20/80, 2\%, and alginate beads has also the high value of gel fraction, but a little bit lower than monolayer hydrogels, which is expected, considering its multicomponent structure and different design.

\subsection{Results of rheological studies}

Rheological measurements were carried out before syneresis and after syneresis. The results of the frequency sweep test before and after syneresis are shown in Fig. 8 and 9. Over the whole frequency range, shear elastic modulus values (G') were above the viscous modulus values (G',) and independent of frequency. It implies the dominant elastic behavior of hydrogels in the linear viscoelastic region. Hydrogels 20/80, 2\% can be observed as the strongest one (Fig. 8 and 9) having the highest values of shear elastic modulus (G'). Rheological, as well as swelling measurements have shown achieved optimized chemical composition of this hydrogel which has been used for the preparation of bilayer sample. The bilayer sample has a dominant elastic nature and optimal mechanical properties in the linear viscoelastic region, considering its design (Fig. 8c). 
Figure 8. Variation of shear elastic (G') and viscous (G', ) moduli versus frequency for a)

CS/AA hydrogels with a different CS/Aac ratio, b) CS/AA hydrogels with different amount of MBAM, c) bilayer hydrogel.

Rheological analysis of hydrogels in the swollen state has revealed that syneresis has taken part during the drying until constant weight. Shear elastic modulus has significantly higher values after syneresis (Fig. 9), which implies a higher density of polymer network and stronger structure. Considering the presence of the same peaks in FTIR spectra before and after syneresis, probably, the hydrogen bonds have been formed, causing the more compact structure. Bilayer sample (Fig. 9c) has significantly higher values of shear elastic modulus in comparison to monolayer samples, which is important from the point of its application. Results of rheological measurements have demonstrated that chitosan hydrogels obtained in this way have significantly higher values of elastic moduli in comparison to chitosan hydrogels obtained using a different synthesis route such as crosslinking by glutaraldehyde [25] or by adding coagulant solution [33].

Figure 9. Variation of shear elastic $\left(G^{\prime}\right)$ and viscous (G'’) moduli versus frequency for a) CS/AA hydrogels with a different CS/AA ratio, b) CS/AA hydrogels with different amount of MBAM, c) bilayer hydrogel after syneresis.

Over the whole frequency range, the loss tangent values are below 0.4, implying a low energy dissipation and dominant elastic behavior before and after syneresis (Fig. 10). The values of $\tan \delta$ are very close before syneresis showing an insignificantly small frequency dependence. After syneresis, these values are lower implying increasing in shear elastic moduli values.

Figure 10. Variation of $\tan \delta$ versus frequency for a) CS/AA hydrogels before syneresis, b) CS/AA hydrogels after syneresis, c) for bilayer hydrogels before and after syneresis. 
Fig. 11 illustrates a complex shear viscosity $\left(\eta^{*}\right)$ in the function of frequency for hydrogel samples before and after syneresis. It can be noticed that $\eta^{*}$ decreases with an increase in frequency indicating a shear-thinning behavior in viscoelastic hydrogels [34]. Considering the power-law model of shear-thinning (pseudoplastic) behavior, the dependence complex shear viscosity on frequency in a given range can be described using the Equation 13:

$\eta^{*}=b \cdot f^{a}$

In order to assess if the complex viscosity depends on the frequency in accordance with Equation 13 , the $\ln \eta *$ were plotted against $\operatorname{lnf}$. Since the plotting of $\ln \eta *$ in the function of $\operatorname{lnf}$ has given a straight line (Fig. S6, Supporting information), the proposed power-law model is adequate. The parameters of the proposed model were presented in Table 5.

Table 4. Parameters of predicted Equation 13.

\begin{tabular}{|c|c|c|c|c|}
\hline \multirow{2}{*}{ Sample } & \multicolumn{2}{|c|}{ Before syneresis } & \multicolumn{2}{c|}{ After syneresis } \\
\cline { 2 - 5 } & $\mathbf{a}$ & $\mathbf{b}$ & $\mathbf{a}$ & $\mathbf{b}$ \\
\hline $15 / 85,2 \%$ & 0.43 & 10.55 & 0.38 & 11.21 \\
\hline $20 / 80,2 \%$ & 0.42 & 10.80 & 0.39 & 11.41 \\
\hline $25 / 75,2 \%$ & 0.43 & 10.33 & 0.39 & 11.41 \\
\hline $20 / 80,1 \%$ & 0.45 & 10.15 & 0.38 & 11.03 \\
\hline $20 / 80,3 \%$ & 0.43 & 10.44 & 0.39 & 10.74 \\
\hline Bilayer & 0.42 & 10.38 & 0.35 & 15.12 \\
\hline
\end{tabular}

Using an Equation 10, the mesh size values are calculated for CS/AA hydrogels before and after synteresis (Table 5). Lower $\xi$ values after syneresis indicate a shorter distance between crosslinking points. 
Table 5. The mesh size $(\xi)$ values of CS/AA hydrogels.

\begin{tabular}{|c|c|c|}
\hline \multirow{2}{*}{ Sample } & \multicolumn{2}{|c|}{$\xi(\AA)$} \\
\cline { 2 - 3 } & $\begin{array}{c}\text { Before } \\
\text { syneresis }\end{array}$ & $\begin{array}{c}\text { After } \\
\text { syneresis }\end{array}$ \\
\hline $15 / 85,2 \%$ & 49 & 39 \\
\hline $20 / 80,2 \%$ & 45 & 37 \\
\hline $25 / 75,2 \%$ & 53 & 37 \\
\hline $20 / 80,1 \%$ & 56 & 42 \\
\hline $20 / 80,3 \%$ & 51 & 46 \\
\hline
\end{tabular}

Mechanical stability of hydrogel samples was also investigated in the regime of shear stress variation. Over the applied stress range (up to 10,000), hydrogels have maintained structural integrity and shear moduli - stress independence in whole investigated range (Fig. 12a and b). In comparison to the other chitosan hydrogels prepared using the other types of crosslinking agents $[10-15,25,34]$ free-radical polymerization gives hydrogels with significantly better mechanical properties. The values of shear elastic moduli are higher after syneresis (Fig. 13) Hydrogel with 1 and 3\% of crosslinking agent have been disintegrated above 10,000 and $2337 \mathrm{~Pa}$, respectively. Bilayer hydrogel has maintained structural integrity up to $10,000 \mathrm{~Pa}$ (Fig. 12) when it has been disintegrated, i.e. stratification has occurred. After syneresis, stratification of bilayer hydrogel has occurred at $336 \mathrm{~Pa}$, but after the values of the moduli had dropped, the bilayer hydrogel has retained its dominant elastic properties.

Figure 12. Variation of shear elastic (G') and viscous (G') moduli versus stress for a) CS/AA hydrogels with a different CS/AA ratio, b) CS/AA hydrogels with different amount of MBAM, c) bilayer hydrogel. 
Figure 13. Variation of shear elastic ( $\left.G^{\prime}\right)$ and viscous $\left(G^{\prime \prime}\right)$ moduli versus stress for a) CS/AA hydrogels with a different CS/AA ratio, b) CS/AA hydrogels with different amount of MBAM, c) bilayer hydrogel after syneresis.

\subsection{Results of extract release studies}

Calibration curve for dependence $\Delta \mathrm{E}_{\mathrm{ab}} *$ of the extract concentration enables the determination of concentration of delivered extract from the bilayer hydrogel (Fig. S7, Supporting Information). The series of standard extract solutions in distilled water was prepared and corresponding $\Delta \mathrm{E}_{\mathrm{ab}} *$ values were read. Linear fitting of the curve gives the Equation 14:

$\Delta E_{a b}^{*}=5.616 \cdot c$

The releasing profile of Allium ursinum L. dry extract from alginate beads loaded in bilayer system can be observed in Fig. 14, expressed as $\Delta \mathrm{E}_{\mathrm{ab}} *$ in the function of time. The initial concentration of wild garlic extract in alginate beads of bilayer hydrogel was $2.4 \mathrm{~g} / \mathrm{l}$. Alginate beads are $\mathrm{pH}$ sensitive systems, those manifest better delivering capacity at $\mathrm{pH} 7.4$ above $\mathrm{pK}_{\mathrm{a}}$ value of alginic acid. The ability of bilayer system to deliver an active compound depend on $\mathrm{pH}$ sensitivity of alginate beads, which gives a proof for realization of idea about chitosan-based bilayer system which realise antimicrobal compound at phisiological conditions $\left(\mathrm{pH} \mathrm{7.4,37}{ }^{\circ} \mathrm{C}\right)$, giving the theotetical platform for application of such system in wound dressing.

Figure 14. $\Delta \mathrm{E}_{\mathrm{ab}}{ }^{*}$ as function of time for bilayer hydrogels at $\mathrm{pH} 3$ and 7.4.

According to the Equation 14, corresponding concentrations for the $\Delta E_{a b}^{*}$ values are summarized in Table 6. 
Table 6. $\Delta E_{a b}^{*}$ and corresponding values of extract concentration.

\begin{tabular}{|c|c|c|c|}
\hline pH 3 & pH 7.4 & pH 3 & pH 7.4 \\
\hline \multicolumn{3}{|c|}{$\Delta \boldsymbol{E}_{\boldsymbol{a b}}^{*}$} & \multicolumn{2}{c|}{$\mathbf{c}(\mathrm{g} / \mathbf{l})$} \\
\hline 5.86 & 8.32 & 0.88 & 1.48 \\
\hline 6.09 & 8.41 & 1.08 & 1.51 \\
\hline 6.29 & 8.81 & 1.12 & 1.57 \\
\hline 7.09 & 8.85 & 1.26 & 1.58 \\
\hline 7.24 & 9.99 & 1.29 & 1.78 \\
\hline
\end{tabular}

\subsection{Results of DSC analysis}

DSC curves of xerogels with different CS/AA ratios are presented in Fig. 15. Xerogels possess the high value of glass transition temperature $\left(\mathrm{T}_{\mathrm{g}}\right)$ which increases with increasing in AA amount in hydrogel composition $\left(143,148,162{ }^{\circ} \mathrm{C}\right.$, respectively), probably due to the higher concentration of hydrogen bonds in hydrogel composition. According to the fact that hydrogels $\mathrm{T}_{\mathrm{g}}$ values are highly above swelling medium temperature, relaxation of polymer chains is slower than diffusion of solvent molecules in a hydrogel matrix and swelling is relaxation-controlled (non-Fickian) [35]. Degradation of hydrogels has occurred in several steps. Comparing the hydrogels with different amounts of crosslinking agent (Fig. 16) it can be noticed that $T_{g}$ value rises with increasing in crosslinking agent amount in hydrogel composition $\left(125,148\right.$ and $153{ }^{\circ} \mathrm{C}$, respectively), due to a higher crosslinking density and lower segmental mobility.

Figure 15. DSC thermograms for hydrogels with different CS/AA ratio: a) 15/85, 2\%, b) 20/80,

$$
2 \%, \text { c) } 25 / 75,2 \%
$$

Figure 16. DSC thermograms for CS/AA hydrogels with different amount of MBAM: a) 20/80,

$$
1 \% \text {, b) } 20 / 80,2 \% \text {, c) } 20 / 80,3 \% \text {. }
$$




\subsection{Results of TG analysis}

The thermogravimetric curves of hydrogels with different CS/AA ratios and different amounts of a crosslinking agent are presented in Fig. 17. The investigated xerogel samples have shown very similar behavior during the thermal decomposition. The three main degradation stages are noticed at thermal curves. The temperature peaks corresponding to the maxima degradation rate at each step are read from the derivative thermogravimetric (DTG) curves, and T5\% (the temperature at which the weight loss is achieved value of 5\%) are listed in Table 7. The first stage, from 25 to $235^{\circ} \mathrm{C}$ corresponds to the water evaporation and smaller side group disintegration. It has resulted with a weight loss up to $5 \%$. The second stage, up to $500{ }^{\circ} \mathrm{C}$, with a weight loss of up to $80 \%$ corresponds to the network disintegration, breaking of amide, ester, and glycosidic linkage [33, 36]. The weight loss in the third stage is attributed to the further decomposition of the chitosan backbone, and it continues until $4.5-7 \%$ of the residual weight. The lowest value of residual weight is noticed for hydrogel $15 / 85,2 \%$ which possess the greatest amount of AA in its composition, while this value for the other samples is in the range between 6.6 and $7 \%$. This sample also possesses the maximal degradation rate which corresponds to the weight loss of $40 \%$.

Figure 17. TGA thermograms of CS/AA hydrogels with different MBAM amounts. 
Table 7. DTG peak maxima values for CS/AA hydrogel samples.

\begin{tabular}{|c|c|c|c|c|c|}
\hline Sample & $15 / 85,2 \%$ & $20 / 80,2 \%$ & $25 / 75,2 \%$ & $20 / 80,1 \%$ & $20 / 80,3 \%$ \\
\hline T5\% $\left({ }^{\circ} \mathrm{C}\right)$ & 211 & 228 & 226 & 226 & 231 \\
\hline $\begin{array}{c}\text { First } \\
\text { stage, } \\
\mathrm{T}_{\max }\left({ }^{\circ} \mathrm{C}\right)\end{array}$ & 191 & 186 & 184 & 184 & 189 \\
\hline $\begin{array}{c}\text { Second } \\
\text { stage, } \\
\mathrm{T}_{\max }\left({ }^{\circ} \mathrm{C}\right)\end{array}$ & 328 & 322 & 320 & 319 & 326 \\
\hline $\begin{array}{c}\text { Third } \\
\text { stage, } \\
\mathrm{T}_{\max },\left({ }^{\circ} \mathrm{C}\right)\end{array}$ & 573 & 569 & 566 & 566 & 571 \\
\hline
\end{tabular}

\subsection{Results of XRD analysis}

XRD measurements were performed in order to investigate the influence of hydrogel composition on the microstructure arrangement. The obtained results have shown that copolymer, as well as hydrogels, possesses similar amorphous morphology. Fig. 18 shows a XRD pattern of CS-graftAA copolymer and Fig. 19 XRD patterns of CS/AA hydrogels. XRD pattern of copolymer shows one broaden peak at $2 \theta=19^{\circ}$. One broad peak at the same position is observed in the hydrogels diffractograms. Based on the position of the amorphous halo peak and the value of radiation wavelength $(1.54 \mathrm{~nm})$ the average interchain spacing $(\langle R>)$ was calculated using Equation 12 [29]. The values of interchain spacing expressed in Angstroms for copolymer and hydrogel samples are listed in Table 8. Hydrogels have similar values of interchain spacing regardless of chitosan/acrylic acid ratio and amount of MBAM in hydrogel composition. A slightly smaller $\langle R\rangle$ is obtained for copolymer (5.67 ̊̊), which implies more efficient chain packaging.

Figure 18. XRD pattern of CS-graft-AA copolymer. 
Figure 19. XRD patterns of hydrogels: a) $15 / 85,2 \%$, b) $20 / 80,2 \%$, c) $25 / 75,2 \%$, d) $20 / 80,1 \%$, e) $20 / 80,3 \%$.

Table 8. Average values of interchain spacing $\langle R\rangle$.

\begin{tabular}{|c|c|}
\hline Sample & $\langle\mathbf{R}\rangle(\mathbf{\AA})$ \\
\hline CS-graft-AA copolymer & 5.67 \\
\hline $15 / 85,2 \%$ & 5.78 \\
\hline $20 / 80,2 \%$ & 5.73 \\
\hline $25 / 75,2 \%$ & 5.70 \\
\hline $20 / 80,1 \%$ & 5.80 \\
\hline $20 / 80,3 \%$ & 5.77 \\
\hline
\end{tabular}

\subsection{Results of statistical analysis}

The results of average values, standard deviation, and range for equilibrium swelling ratio (ESR), and gel fraction for hydrogel samples are summarized in Table 9. The standard deviation is in the range between 0.38 and 2.00, which implies relatively low dissipation of results. Standard Error values for intercept and slope of curves fitted for determination of diffusional exponent (n) are given in Fig. S2 and S3 in Supporting Information, while Fig. S4 and S5 show Standard Error for intercept and slope of linear fitted curves for determination of second-order swelling kinetics, $K_{2}$. Table 10 shows the statistical analysis of color parameter $\Delta \mathrm{E}_{\mathrm{ab}} *$ at two $\mathrm{pH}$ values (3 and 7.4) for the bilayered sample with an active compound. Statistical analysis of elastic plateau values of shear elastic modulus before and after syneresis for hydrogel samples is given in Table S1, Supporting Information 
Table 9. Average values of ESR at different $\mathrm{pH}(3$ and 7.4$)$ and temperatures $\left(25\right.$ and $\left.37^{\circ} \mathrm{C}\right)$ and gel fraction, with standard deviation and range.

\begin{tabular}{|c|c|c|c|c|c|}
\hline Sample & $\begin{array}{c}\text { ESR at } \\
\text { pH } 3 \\
\left(25^{\circ} \mathrm{C}\right)\end{array}$ & $\begin{array}{c}\text { ESR at } \\
\text { pH } 7.4 \\
\left(25^{\circ} \mathrm{C}\right)\end{array}$ & $\begin{array}{c}\text { ESR at } \\
\text { pH } 3 \\
\left(37^{\circ} \mathrm{C}\right)\end{array}$ & $\begin{array}{c}\text { ESR at } \\
\text { pH } 7.4 \\
\left(37^{\circ} \mathrm{C}\right)\end{array}$ & $\begin{array}{c}\text { Gel } \\
\text { fraction }\end{array}$ \\
\hline $15 / 85,2 \%$ & 52.93 & 100.79 & 58.18 & 131.03 & 98.14 \\
\hline $\begin{array}{l}\text { Standard } \\
\text { Deviation }\end{array}$ & 0.57 & 1.49 & 1.97 & 1.00 & 0.4 \\
\hline Range & 1.15 & 2.99 & 3.94 & 2.02 & 0.8 \\
\hline $20 / 80,2 \%$ & 34.38 & 47.11 & 48.13 & 68.79 & 98.61 \\
\hline $\begin{array}{c}\text { Standard } \\
\text { Deviation }\end{array}$ & 0.32 & 0.90 & 2.00 & 0.49 & 0.09 \\
\hline Range & 0.64 & 1.81 & 4.02 & 0.97 & 0.19 \\
\hline $25 / 75,2 \%$ & 34.55 & 39.97 & 44.91 & 54.76 & 97.68 \\
\hline $\begin{array}{l}\text { Standard } \\
\text { Deviation }\end{array}$ & 0.55 & 0.57 & 0.51 & 0.56 & 0.56 \\
\hline Range & 1.09 & 1.14 & 1.02 & 1.11 & 0.56 \\
\hline $20 / 80,1 \%$ & 39.76 & 46.25 & 53.48 & 63.22 & 97.28 \\
\hline $\begin{array}{l}\text { Standard } \\
\text { Deviation }\end{array}$ & 1.5 & 1.25 & 0.98 & 1.11 & 0.39 \\
\hline Range & 3 & 2.5 & 1.95 & 2.22 & 0.78 \\
\hline $20 / 80,3 \%$ & 31.48 & 35.46 & 41.56 & 46.09 & 98.43 \\
\hline $\begin{array}{c}\text { Standard } \\
\text { Deviation }\end{array}$ & 1.23 & 0.99 & 0.54 & 1.00 & 0.31 \\
\hline Range & 2.46 & 1.99 & 1.09 & 2.00 & 0.62 \\
\hline $\begin{array}{l}\text { Bilayered } \\
\text { hydrogel }\end{array}$ & 43.35 & 68.59 & 67.35 & 143.88 & 96.56 \\
\hline $\begin{array}{l}\text { Standard } \\
\text { Deviation }\end{array}$ & 1.19 & 0.98 & 0.94 & 0.77 & 0.56 \\
\hline Range & 2.35 & 1.95 & 1.89 & 1.49 & 0.69 \\
\hline
\end{tabular}


Table 10. Average values of color parameter $\Delta \mathrm{E}_{\mathrm{ab}}{ }^{*}$ at different $\mathrm{pH}$ (3 and 7.4) and physiological temperature $\left(37^{\circ} \mathrm{C}\right)$ with standard deviation and range.

\begin{tabular}{|c|c|c|}
\hline Sample & $\begin{array}{c}\Delta E_{a b}^{*} \text { at pH } \\
\mathbf{3}\left(37^{\circ} \mathbf{C}\right)\end{array}$ & $\begin{array}{l}\Delta E_{a b}^{*} \text { at } p H \\
7.4\left(37^{\circ} \mathrm{C}\right)\end{array}$ \\
\hline $15 / 85,2 \%$ & 5.86 & 8.32 \\
\hline $\begin{array}{c}\text { Standard } \\
\text { Deviation }\end{array}$ & 0.25 & 0.28 \\
\hline Range & 0.25 & 0.56 \\
\hline $20 / 80,2 \%$ & 6.09 & 8.41 \\
\hline $\begin{array}{c}\text { Standard } \\
\text { Deviation }\end{array}$ & 0.29 & 0.26 \\
\hline Range & 0.58 & 0.51 \\
\hline $25 / 75,2 \%$ & 6.29 & 8.81 \\
\hline $\begin{array}{c}\text { Standard } \\
\text { Deviation }\end{array}$ & 0.11 & 0.15 \\
\hline Range & 0.22 & 0.2 \\
\hline $20 / 80,1 \%$ & 7.09 & 8.85 \\
\hline $\begin{array}{c}\text { Standard } \\
\text { Deviation }\end{array}$ & 0.11 & 0.17 \\
\hline Range & 0.22 & 0.32 \\
\hline $20 / 80,3 \%$ & 7.24 & 9.99 \\
\hline $\begin{array}{c}\text { Standard } \\
\text { Deviation }\end{array}$ & 0.22 & 0.26 \\
\hline Range & 0.44 & 0.52 \\
\hline
\end{tabular}

\section{Conclusions}

Chitosan-based hydrogels were prepared via free-radical polymerization, using a simple and economical two-step method. The first step has implied grafting of chitosan using an acrylic acid in order to get branched copolymer with incorporated double bonds able to form a hydrophilic network in the presence of crosslinking agent such as MBAM. Grafting reaction carried out by amidation and esterification reactions was confirmed by FTIR method. Obtained hydrogels have 
shown similar swelling behavior at different $\mathrm{pH}$ values, dominant elastic behavior, and excellent mechanical properties. According to the diffusional exponent values, solvent sorption into the hydrogels is non-Fickian, and swelling kinetics follows the second order. Amplitude sweep tests have shown the high mechanical stability of hydrogels. Variation in complex viscosity in the function of frequency has shown pseudoplastic (shear-thinning) behavior in viscoelastic material. In order to get a $\mathrm{pH}$-sensitive system intended for potential application in wound dressing based on the strong chitosan gels, the novel design of bilayer chitosan hydrogels with embedded alginate beads was prepared. Hydrogel 20/80, $2 \%$ was used for layers, because it has shown the best properties - optimal crosslinking, the strongest nature. The bilayered system has demonstrated the ability for $\mathrm{pH}$-dependant releasing of an active compound - Allium ursinum L. dried extract. Rheological measurements have demonstrated strong nature, as a consequence of coherent juncture between layers.

\section{Notes}

The authors declare no competing financial interest.

\section{ACKNOWLEDGMENT}

This study was supported by Ministry of Education, Science and Technological Development, Republic of Serbia, project number 451-03-68/2020-14/ 200134 for financial support.

\section{References}

[1] Kopecek J (2002) Polymer chemistry: swell gels. Nature 417:388-391. https://doi.org/10.1038/417388a.388

[2] Enas MA (2015) Hydrogel: Preparation, characterization, and applications: A review. J Adv Res 6:105-121. https://doi.org/10.1016/j.jare.2013.07.006 
[3] Ullah MBH, Othman F, Javed Z, Ahmad HM (2015) Classification, processing and application of hydrogels: A review. Mater Sci Eng C. 57:414-433. https://doi.org/10.1016/j.msec.2015.07.053 [4] Okay O, Sariişik SB, Sibel DZ (1998) Swelling behavior of anionic acrylamide-based hydrogels in aqueous salt solutions: Comparison of experiment with theory. J Appl Polym Sci 70:567-575.

https://doi.org/10.1002/(SICI)1097-4628(19981017)70:3<567::AIDAPP19>3.0.CO;2-Y

[5] Erceg T, Dapčević-Hadnađev T, Hadnađev M, Ristić I (2021) Swelling kinetics and rheological behaviour of microwave synthesized poly(acrylamide-co-acrylic acid) hydrogels. Colloid Polym Sci 299:11-23. https://doi.org/10.1007/s00396-020-04763-9

[6] Hamedi H, Moradi S, Hudson SM, Tonelli AE (2018) Chitosan based hydrogels and their applications for drug delivery in wound dressings: A review. Carbohydr Polym 199:445-460. https://doi.org/10.1016/j.carbpol.2018.06.114

[7] Jayakumar R, Prabaharan M, Sudheesh Kumar PT, Nair SV, Tamura H (2011) Biomaterials based on chitin and chitosan in wound dressing applications. Biotechnol Adv. 29:322-337. https://doi.org/10.1016/j.biotechadv.2011.01.005

[8] Souza RD, Zahedi P, Allen CJ, Miller MP (2009) Biocompatibility of injectable chitosanphospholipid implant systems. Biomaterials 30:3818-3824.

https://doi.org/10.1016/j.biomaterials.2009.04.003

[9] Paul W, Sharma CP (2004) Chitosan and Alginate Wound Dressings: A Short Review. Trends Biomater Artif Organs. 18:18-23. 
[10] Milosavljević NB, Kljajević LM, Popović IG, Filipović JM, Kalagasidis Krušić MT (2010) Chitosan, itaconic acid and poly(vinyl alcohol) hybrid polymer networks of high degree of swelling and good mechanical strength. Polym Int 59:686-694. https://doi.org/10.1002/pi.2756 [11] Zhang Y, Guan Y, Zhou S (2005) Single Component Chitosan Hydrogel Microcapsule from a Layer-by-Layer Approach. Biomacromolecules. 6:2365-2369. https://doi.org/10.1021/bm050058b

[12] Muzzarelli RAA (2009) Genipin-crosslinked chitosan hydrogels as biomedical and pharmaceutical aids. Carbohydr. Polym. 2009:1-9. https://doi.org/10.1016/j.carbpol.2009.01.016 [13] Liu R, Xu X, Zhuang X, Cheng B (2014) Solution blowing of chitosan/PVA hydrogel nanofiber mats. Carbohydr Polym 101:1116-1121. https://doi.org/10.1016/j.carbpol.2013.10.056 [14] Prabaharan M, Mano JF (2006) Chitosan derivatives bearing cyclodextrin cavitiesas novel adsorbent matrices. Carbohydr Polym. 63:153-166. https://doi.org/10.1016/j.carbpol.2005.08.051 [15] Xie W, Xu PX, Lu Q (2001) Antioxidant activity of water-soluble chitosan derivatives. Bioorg Med Chem Lett. 11:1699 - 1701. https://doi.org/10.1016/s0960-894x(01)00285-2

[16] Zhao L, Mitomo H (2008) Synthesis of pH-Sensitive and Biodegradable CMCellulose/Chitosan Polyampholytic Hydrogels with Electron Beam Irradiation. J Bioact Compat Polym. 23:319-333. https://doi.org/10.1177/0883911508092302

[17] Chen Y, Zhang Y, Wang F., Meng W, Yang X, Li P, Jiang J, Tan H, Zheng Y (2016) Preparation of porous carboxymethyl chitosan grafted poly (acrylic acid) superabsorbent by solvent precipitation and its application as a hemostatic wound dressing. Mater Sci Eng C Mater Biol Appl. 63:18-29. https://doi.org/10.1016/j.msec.2016.02.048

[18] Chen Y, Tan HM (2006) Crosslinked carboxymethylchitosan-g-poly(acrylic acid) copolymer as a novel superabsorbent polymer. Carbohydr Res. 341:887-896. 
https://doi.org 10.1016/j.carres.2006.01.027

[19] Cheng B, Pei B, Wang Z, Hu Q (2017) Advances in chitosan-based superabsorbent hydrogels RSC Adv. 7: 42036-42046. https://doi.org/10.1039/C7RA07104C

[20] Draget KI, Taylor C (2011) Chemical, physical and biological properties of alginates and their biomedical implications. Food Hydrocoll. 25:251-256.

https://doi.org/10.1016/j.foodhyd.2009.10.007

[21] Draget KI, Braek GS, Smidsrod O (1994) Alginic acid gels: the effect of alginate chemical composition and molecular weight. Carbohydr.Polym. 25:31-38. https://doi.org/10.1016/01448617(94)90159-7

[22] Tomšik A, Drying and extraction of the wild garlic leaves (Allium ursinum L.) in order to obtain functional products with bioactive potential. Doctoral dissertation, University of Novi Sad, Novi Sad, 2018.

[23] Reed RW, Reed GB (1948) Drop plate method of counting viable bacteria. Can J Res. 26:317326. https://doi.org/10.1139/cjr48e-020

[24] Peppas NA, Bures P, Leobandung W, Ichikawa H (2000) Hydrogels in pharmaceutical formulations. Eur J Pharm Biopharm. 50: 27-46. https://doi.org/10.1016/s0939-6411(00)00090-4 [25] Bajpai AK, Shukla SK, Bhanu S, Kankane S (2008) Counterion Binding in Aqueous Solutions of Poly(vinylpyridines) as Assessed by Potentiometric Titration. Prog Polym Sci. 33:1088-1118. http://dx.doi.org/10.1016/j.progpolymsci.2008.07.005

[26] Quintana JR, Valderruten NE, Katime I (1999) Synthesis and swelling kinetics of poly(dimethylaminoethyl acrylate methyl chloride quaternary-co-itaconic acid) hydrogels. Langmuir 15:4728-4730. https://doi.org/10.1021/la980982+ 
[27] Pescosolido L, Feruglio L, Farra R, Fiorentino S, Colombo I, Coviello T, Matricardi PW, Hennink WE, Vermonden T, Grassi M (2012) Mesh size distribution determination of interpenetrating polymer network hydrogels. Soft Matter. 8:7708-7715.

https://doi.org/10.1039/C2SM25677K

[28] Belović M, Mastilović J, Kevreša Ž (2014) Change of surface colour parameters during storage of paprika (Capsicum annuum L.). Food and Feed Res. 41:85-92. https://doi.org/10.5937/FFR1402085B

[29] Halasa AF, Wathen GD, Hsu W, Matrana A, Massie JM (1991) J Appl Polym. Sci. 43:183190. https://doi.org/10.1002/app.1991.070430115

[30] Erceg T, Cakić S, Cvetinov M, Dapčević Hadnađev T, Budinski-Simendić J, Ristić I (2020) The properties of conventionally and microwave synthesized poly(acrylamide-co-acrylic acid) hydrogels. Polym Bull 77:2089-2110. https://doi.org/10.1007/s00289-019-02840-w

[31] Varma R, Vasudevan S (2020) Extraction, Characterization, and Antimicrobial Activity of Chitosan from Horse Mussel Modiolus modiolus. ACS Omega 5:20224-20230. https://doi.org/10.1021/acsomega.0c01903 [32] Wang QZ, Chen XG, Liu N, Wang SX, Liu CS, Meng XH, Liu CG (2006) Protonation constants of chitosan with different molecular weight and degree of deacetylation. Carbohydr.Polym. 65:194-201. https://doi.org/10.1016/j.carbpol.2006.01.001

[33] Wyrzykowski D, Hebanowska E, Nowak-Wiczk G, Makowski M, Chmurzynski L (2011) Thermal behaviour of citric acid and isomeric aconitic acids. J Therm Anal Calorim. 104:731-735. https://doi.org/10.1007/s10973-010-1015-2

[34] Cuomo F, Cofelice M, Lopez F (2019) Rheological characterization of hydrogels from alginate-based nanodispersion. Polymers 11:259. https://doi.org/10.3390/polym11020259 
[35] S. Bashir, Y.Y. Teo, S. Ramesh, K. Ramesh, M. Rizwan, M. Rizwan, J. Chil. Chem. Soc., 2019, 64 (3): 4571

[36] Erceg T, Stupar A, Cvetinov M, Vasić V, Ristić I (2021) Investigation the correlation between chemical structure and swelling, thermal and flocculation properties of carboxymethylcellulose hydrogels. J Appl Polym Sci. 138:50240 https://doi.org/10.1002/app.50365

\section{Figures}

Figure 1. Preparation of bilayer hydrogel.

Figure 2. Proposed reaction mechanism of CS-graft-AA hydrogels synthesis.

Figure 3. FTIR spectra of: I a) CS/AA copolymer 20/80, b) CS/AA hydrogel 20/80; II CS/AA hydrogels a) $15 / 85,2 \%$, b) $20 / 80,2 \%$, c) $25 / 75,2 \%$ III a) $20 / 90,1 \%$, b) $20 / 80,2 \%$, c) $20 / 80,3 \%$

Figure 4. SEM images of CS/AA hydrogels at magnification 10000: a) hydrogel 15/85, 2\%, b) hydrogel $20 / 80,2 \%$, c) $25 / 75,2 \%$ d) $20 / 80,1 \%$, e) $20 / 80,3 \%$.

Figure 5. SEM images of alginate beads at different magnifications.

Figure 6. Swelling ratio as a function of time for CS/AA hydrogels at room temperature a) with different amount of grafted $\mathrm{AA}$ at $\mathrm{pH} \mathrm{3,b)} \mathrm{with} \mathrm{different} \mathrm{amount} \mathrm{of} \mathrm{cross} \mathrm{linking} \mathrm{agent} \mathrm{at} \mathrm{pH} 3$, c) with different amount of grafted $\mathrm{AA}$ at $\mathrm{pH} 7.4$, d) with different amount of crosslinking agent at $\mathrm{pH} 7.4$.

Figure 7. Swelling ratio as a function of time for bilayered hydrogel at physiological temperature and different $\mathrm{pH}$ values ( $\mathrm{pH} 3$ and $\mathrm{pH}$ 7.4).

Figure 8. Variation of shear elastic (G') and viscous (G', ) moduli versus frequency for a) CS/AA hydrogels with a different CS/Aac ratio, b) CS/AA hydrogels with different amount of MBAM, c) bilayer hydrogel. 
Figure 9. Variation of shear elastic $(G$ ') and viscous (G') moduli versus frequency for a) CS/AA hydrogels with a different CS/AA ratio, b) CS/AA hydrogels with different amount of MBAM, c) bilayer hydrogel after syneresis.

Figure 10. Variation of $\tan \delta$ versus frequency for a) CS/AA hydrogels before syneresis, b) CS/AA hydrogels after syneresis, c) for bilayer hydrogels before and after syneresis.

Figure 11. Complex shear viscosity $\left(\eta^{*}\right)$ versus frequency for CS/AA hydrogels a) before syneresis, b) after syneresis, c) bilayer hydrogel before syneresis d) bilayer hydrogel after syneresis.

Figure 12. Variation of shear elastic (G') and viscous (G') moduli versus stress for a) CS/AA hydrogels with a different CS/AA ratio, b) CS/AA hydrogels with different amount of MBAM, c) bilayer hydrogel.

Figure 13. Variation of shear elastic (G') and viscous (G') moduli versus stress for a) CS/AA hydrogels with a different CS/AA ratio, b) CS/AA hydrogels with different amount of MBAM, c) bilayer hydrogel after syneresis.

Figure 14. $\Delta \mathrm{E}_{\mathrm{ab}}{ }^{*}$ as function of time for bilayer hydrogels at $\mathrm{pH} 3$ and 7.4.

Figure 15. DSC thermograms for hydrogels with different CS/AA ratio: a) 15/85, 2\%, b) 20/80, $2 \%$, c) $25 / 75,2 \%$.

Figure 16. DSC thermograms for CS/AA hydrogels with different amount of MBAM: a) 20/80, $1 \%$, b) $20 / 80,2 \%$, c) $20 / 80,3 \%$.

Figure 17. TGA thermograms of CS/AA hydrogels with different MBAM amounts.

Figure 18. XRD pattern of CS-graft-AA copolymer.

Figure 19. XRD patterns of hydrogels: a) $15 / 85,2 \%$, b) $20 / 80,2 \%$, c) $25 / 75,2 \%$, d) $20 / 80,1 \%$, e) $20 / 80,3 \%$. 


\section{Tables}

Table 1. The initial amount of components for the synthesis of CS/AA hydrogels.

Table 2. The diffusional exponent ( $n$ ) values for CS/AA hydrogel samples ( $\mathrm{pH} 3$ and 7.4, at room temperature and physiological temperature).

Table 3. Estimated $K_{2}$ values for the second - order kinetics (Equation 4).

Table 4. Parameters of predicted Equation 13.

Table 5. The mesh size $(\xi)$ values of CS/AA hydrogels.

Table 6. $\Delta E_{a b}^{*}$ and corresponding values of extract concentration.

Table 7. DTG peak maxima values for CS/AA hydrogel samples.

Table 8. Average values of interchain spacing $\langle R\rangle$.

Table 9. Average values of ESR at different $\mathrm{pH}(3$ and 7.4$)$ and temperatures $\left(25\right.$ and $\left.37^{\circ} \mathrm{C}\right)$ and gel fraction, with standard deviation and range.

Table 10. Average values of color parameter $\Delta \mathrm{E}_{\mathrm{ab}}{ }^{*}$ at different $\mathrm{pH}$ (3 and 7.4) and physiological temperature $\left(37^{\circ} \mathrm{C}\right)$ with standard deviation and range. 



\section{Figures}

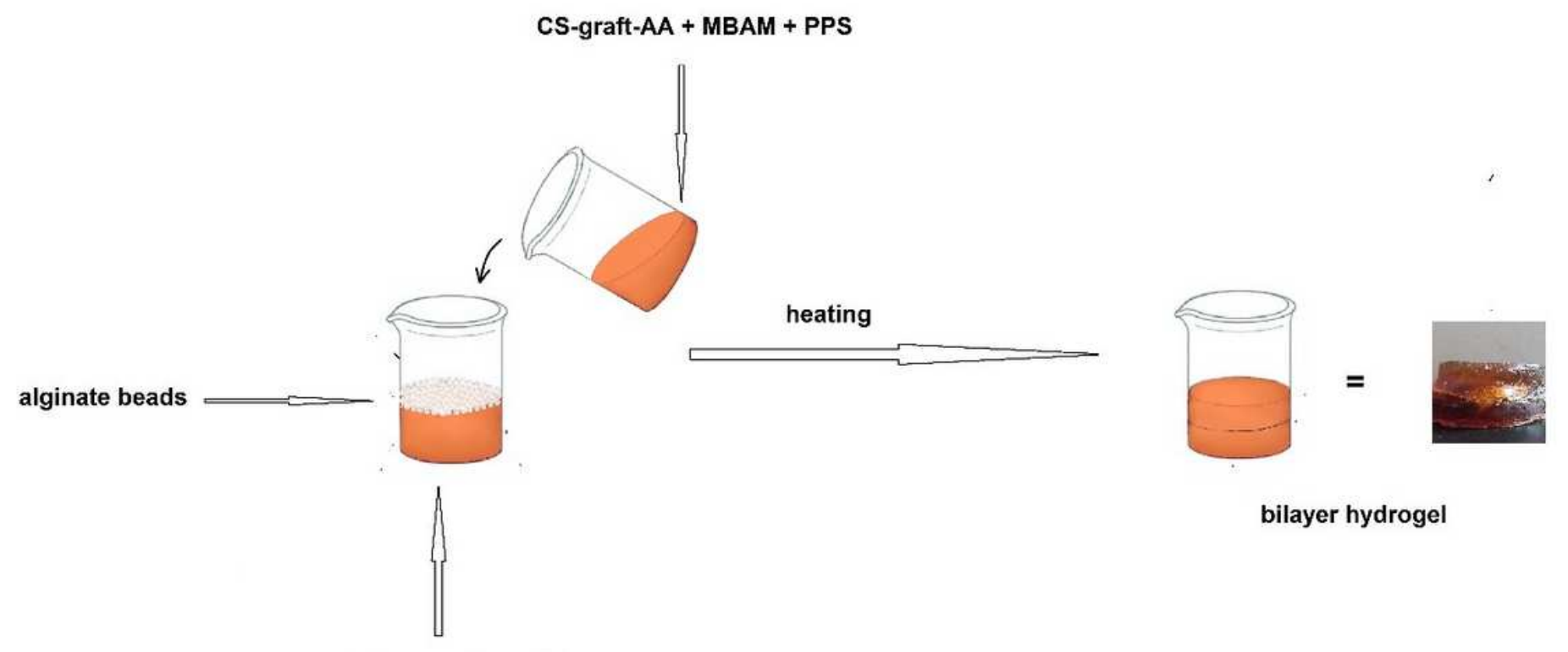

hydrogel $20 / 80,2 \%$

\section{Figure 1}

Preparation of bilayer hydrogel.

\section{Figure 2}

Proposed reaction mechanism of CS-graft-AA hydrogels synthesis.

Figure 3

FTIR spectra of: I a) CS/AA copolymer 20/80, b) CS/AA hydrogel 20/80; II CS/AA hydrogels a) 15/85, 2\%, b) $20 / 80,2 \%$, c) $25 / 75,2 \%$ III a) $20 / 90,1 \%$, b) $20 / 80,2 \%$, c) $20 / 80,3 \%$

\section{Figure 4}

SEM images of CS/AA hydrogels at magnification 10000: a) hydrogel $15 / 85,2 \%$, b) hydrogel $20 / 80,2 \%$, c) $25 / 75,2 \%$ d) $20 / 80,1 \%$, e) $20 / 80,3 \%$. 


\section{Figure 5}

SEM images of alginate beads at different magnifications.

\section{Figure 6}

Swelling ratio as a function of time for CS/AA hydrogels at room temperature a) with different amount of grafted $\mathrm{AA}$ at $\mathrm{pH} 3, \mathrm{~b}$ ) with different amount of cross linking agent at $\mathrm{pH} 3, \mathrm{c}$ ) with different amount of grafted $\mathrm{AA}$ at $\mathrm{pH} 7.4, \mathrm{~d}$ ) with different amount of crosslinking agent at $\mathrm{pH}$ 7.4.

\section{Figure 7}

Swelling ratio as a function of time for bilayered hydrogel at physiological temperature and different $\mathrm{pH}$ values ( $\mathrm{pH} 3$ and $\mathrm{pH} 7.4)$.

\section{Figure 8}

Variation of shear elastic ( $\left.G^{\prime}\right)$ and viscous ( $\left.G^{\prime \prime}\right)$ moduli versus frequency for a) CS/AA hydrogels with a different CS/Aac ratio, b) CS/AA hydrogels with different amount of MBAM, c) bilayer hydrogel.

\section{Figure 9}

Variation of shear elastic (G') and viscous (G") moduli versus frequency for a) CS/AA hydrogels with a different CS/AA ratio, b) CS/AA hydrogels with different amount of MBAM, c) bilayer hydrogel after syneresis. 


\section{Figure 10}

Variation of tan $\delta$ versus frequency for a) CS/AA hydrogels before syneresis, b) CS/AA hydrogels after syneresis, c) for bilayer hydrogels before and after syneresis.

\section{Figure 11}

Complex shear viscosity $\left(\eta^{\star}\right)$ versus frequency for CS/AA hydrogels a) before syneresis, b) after syneresis, c) bilayer hydrogel before syneresis d) bilayer hydrogel after syneresis.

\section{Figure 12}

Variation of shear elastic (G') and viscous (G") moduli versus stress for a) CS/AA hydrogels with a different CS/AA ratio, b) CS/AA hydrogels with different amount of MBAM, c) bilayer hydrogel.

\section{Figure 13}

Variation of shear elastic ( $\left.G^{\prime}\right)$ and viscous (G") moduli versus stress for a) CS/AA hydrogels with a different CS/AA ratio, b) CS/AA hydrogels with different amount of MBAM, $c$ ) bilayer hydrogel after syneresis.

\section{Figure 14}

$\Delta$ Eab* as function of time for bilayer hydrogels at $\mathrm{pH} 3$ and 7.4.

\section{Figure 15}

DSC thermograms for hydrogels with different CS/AA ratio: a) $15 / 85,2 \%$, b) $20 / 80,2 \%$, c) $25 / 75,2 \%$. 
DSC thermograms for CS/AA hydrogels with different amount of MBAM: a) $20 / 80,1 \%, b) 20 / 80,2 \%$, c) $20 / 80,3 \%$.

\section{Figure 17}

TGA thermograms of CS/AA hydrogels with different MBAM amounts.

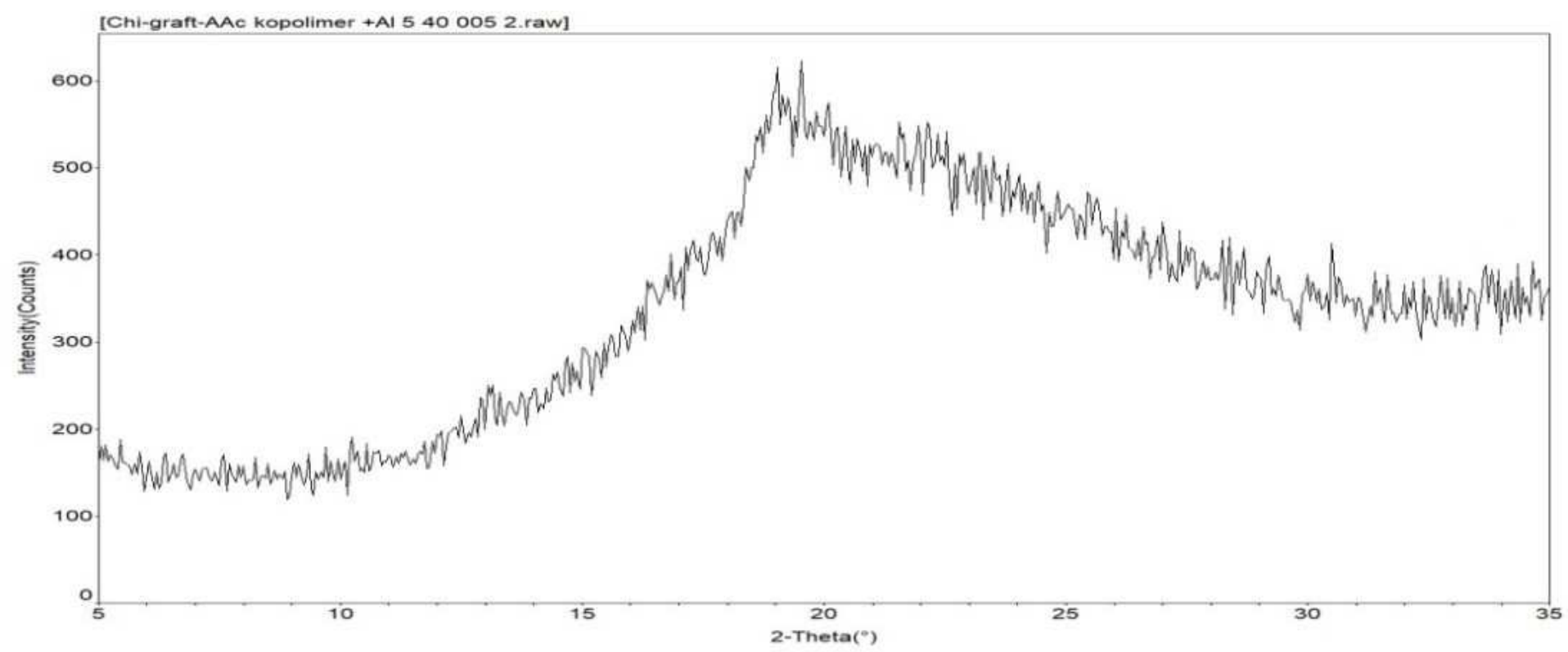

Figure 18

XRD pattern of CS-graft-AA copolymer.

Figure 19

XRD patterns of hydrogels: a) $15 / 85,2 \%$, b) $20 / 80,2 \%$, c) $25 / 75,2 \%$, d) $20 / 80,1 \%$, e) $20 / 80,3 \%$.

\section{Supplementary Files}

This is a list of supplementary files associated with this preprint. Click to download.

- Supportinginformation.docx 